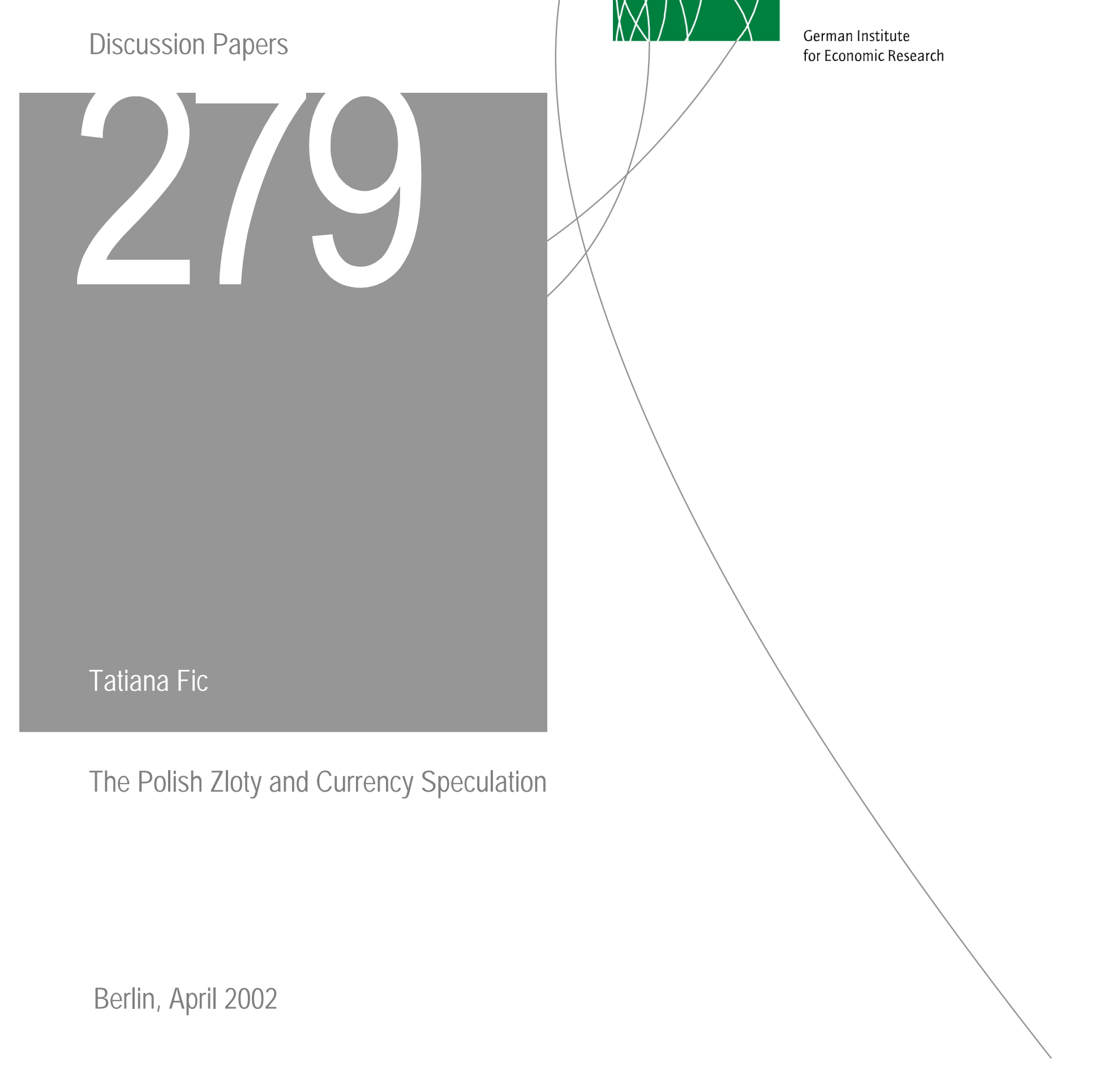


Opinions expressed in this paper are those of the author and do not necessarily reflect views of the Institute.

\section{DIW Berlin}

German Institute

for Economic Research

Königin-Luise-Str. 5

14195 Berlin,

Germany

Phone $+49-30-89789-0$

Fax +49-30-897 89-200

www.diw.de

ISSN 1619-4535 


\title{
The Polish Zloty and Currency Speculation
}

\author{
Tatiana Fic*
}

\begin{abstract}
This paper uses Markov switching models to study short-run movements of the Polish zloty and speculative phenomena in Poland, that is, to investigate whether the exchange rate is "contaminated" by a speculative bubble. The zloty movements are examined in terms of so-called long swings - periods of prevailing appreciation and depreciation of the exchange rate. Speculative fluctuations of the zloty are investigated within two different frameworks: the uncovered interest parity hypothesis and a model of a zloty bubble. The results obtained suggest that the zloty exchange rate is characterised by interweaving periods of appreciation and depreciation with different durations. The uncovered interest parity hypothesis does not hold. Periods were identified, in which the zloty exhibited "bubble properties".
\end{abstract}

Keywords: Markov switching, exchange rates, speculative bubbles JEL classification: C32, F31

* National Bank of Poland. The final version of the paper was completed during the author's research stay at the German Institut of Economic Research (DIW Berlin). The author wishes to thank Prof. A. Welfe, P. Szpunar, D. Tymoczko, O. Szczepańska, G.A. Horn, M. Schrooten and K. Lommatzsch for useful comments on earlier drafts of the paper. The views expressed in the paper are those of the author and do not necessarily reflect those of the National Bank of Poland. 


\section{Introduction}

The globalisation of financial markets in conjunction with the development of derivatives and the liberalisation of capital flows make currencies, and among them the zloty, vulnerable to speculative activities of currency market participants, and may lead to the emergence of exchange rate bubbles. A speculative bubble can be defined as a difference between the exchange rate level that corresponds to the current economic situation, and the exchange rate level that results from currency speculation, that is, market participants' activities oriented at artificial strengthening or weakening of the currency.

The complexity of processes determining exchange rate behaviour makes detecting speculative bubbles highly problematic. There is still little agreement on how to specify the fundamentals, and it is difficult to find an adequate econometric model that would accommodate the complicated dynamics of exchange rate bubble behaviour. It is also necessary to take into consideration stochastic properties of the exchange rates, essential from the viewpoint of empirical investigation.

Following Hall et al. [1999] existing tests on bubbles could be divided into direct and indirect tests.

The direct tests require a specification of a bubble model and estimation of its parameters (see e.g. Flood, Garber [1980]). A shortcoming of these tests is their insensitivity to flawed model specification. Incorrectly defined causal inferences automatically lead to misleading conclusions about the bubbles existence, since the tests are not powerful enough to cope with differently specified bubbles.

The indirect tests are based on different assumptions. One does not define a bubble explicite, but investigates, whether the observed exchange rate exhibits bubble properties. The indirect tests include Markov switching unit root tests (see Funke, Hall, Sola [1994], Hall et al. [1999]), regime switching regression (see van Norden [1996]) and variance bounds tests (see Schiller [1981]).

The objective of the paper is to construct an econometric model that would permit investigation of the zloty behaviour, and its susceptibility to speculation in particular. The adopted approach is based on daily movements of the zloty, which implies that the core of the study relates to the short-run zloty fluctuations and exchange rate bubbles that should be understood in terms of speculation on the financial markets rather than long term macroeconomic disequilibrium. The remainder of the paper is organised as follows. Section 
II outlines the structure of the regime-switching model, which is a starting point for an analysis of the zloty movements and construction of the exchange rate bubble model. Further sections provide empirical results. Section III focuses on the behaviour of the zloty in terms of the so-called long swings - periods of prevailing appreciation and depreciation of the exchange rate. Uncovered interest parity hypothesis is examined in section IV. A model of a zloty bubble is developed in section $\mathrm{V}$ - rate of return on 5 year bonds, risk premium and the zloty forward rate provide a setting, within which the zloty exchange rate is examined. Last section concludes.

\section{The model}

The starting point for the modelling strategy adopted in this paper is a regime-switching model. Its specific structure allows for an elastic modelling of the exchange rate dynamics as well as a clear interpretation of the obtained results.

Regime-switching models are parameter-varying models. Parameter changes occur simultaneously with the regime changes, which determine the direction and/or the strength of the investigated relations. Thus, when building a model, a number of regimes (states), generating the endogenous variable's movements, and the law of the dynamics of regime changes should be specified.

The zloty exchange rate analysis is based on a regime-switching model developed by Hamilton [1994]. The idea of the model is to decompose a time series into a sequence of stochastic trends, corresponding to growth or decline regimes, with unobservable regime changes following a Markov chain. The aim of the estimation is thus to determine the vector of parameters that includes means and variances for both states and transition probabilities between them.

Consider a stochastic process of the form:

$$
\tilde{y}_{t}=n_{t}+\tilde{z}_{t},
$$

where:

$\tilde{y}_{t}$ - dependent variable,

$n_{t}$ - Markov trend,

$\tilde{z}_{t}$ - random component.

The components of the model fulfil the following assumptions. 
Firstly, $n_{t}$ is the so-called Markov trend, that is, a random walk with drift following a Markov process:

$$
n_{t}=\mu\left(s_{t}\right)+n_{t-1}=\alpha_{0}+\alpha_{1} s_{t}+n_{t-1},
$$

where $s_{t}$ - regime variable, $s_{t} \in\{0,1\}$,

and:

$$
\begin{aligned}
& P\left(s_{t}=1 \mid s_{t-1}=1\right)=p, \\
& P\left(s_{t}=0 \mid s_{t-1}=1\right)=1-p, \\
& P\left(s_{t}=1 \mid s_{t-1}=0\right)=1-q, \\
& P\left(s_{t}=0 \mid s_{t-1}=0\right)=q .
\end{aligned}
$$

The above set of equations implies that there are two distributions that the particular observation on the dependent variable can be drawn from. The first $m_{1}$ observations can be generated by regime 0 , the next $m_{2}$ - by regime 1 , the next $m_{3}$ - by regime 0 , etc. The values of $m_{i}^{\prime} s, i=1,2, \ldots, M$, where $M$ denotes number of switching points, are unknown, since one has no a priori knowledge about how to classify the data between the regimes.

Secondly, the random component $\tilde{z}_{t}$ is an $\operatorname{ARIMA}(r, 1,0)$ process:

$$
\tilde{z}_{t}-\tilde{z}_{t-1}=\varphi_{1}\left(\tilde{z}_{t-1}-\tilde{z}_{t-2}\right)+\varphi_{2}\left(\tilde{z}_{t-2}-\tilde{z}_{t-3}\right)+. .+\varphi_{r}\left(\tilde{z}_{t-r}-\tilde{z}_{t-r-1}\right)+\varepsilon_{t},
$$

where:

$\varepsilon_{t}$ - strict white noise,

i.e. $\mathrm{E}\left(\varepsilon_{t}\right)=0, \operatorname{var}\left(\varepsilon_{t}\right)=\sigma^{2}, \operatorname{cov}\left(\varepsilon_{t}, \varepsilon_{t+k}\right)=0$, and $\varepsilon_{t}$ and $\varepsilon_{t+k}$ are independently distributed.

Differentiating equation (1) yields:

$$
\tilde{y}_{t}-\tilde{y}_{t-1}=n_{t}-n_{t-1}+\tilde{z}_{t}-\tilde{z}_{t-1} .
$$

and replacing:

$$
\begin{aligned}
& y_{t}=\tilde{y}_{t}-\tilde{y}_{t-1}, \\
& z_{t}=\tilde{z}_{t}-\tilde{z}_{t-1},
\end{aligned}
$$

enables the following model simplification:

$$
y_{t}=\alpha_{0}+\alpha_{1} s_{t}+z_{t} \text {. }
$$

It is only $y_{t}$, that is observable and the purpose is to estimate transition probabilities between states, parameters $\alpha_{0}, \alpha_{1}$, denoting mean levels of $y_{t}$ in both regimes and variances of their random components. 
The Hamilton model is estimated with the ML method, the Hamilton filter, the Kim's smoothing algorithm and the EM algorithm (Expectation Step, Maximisation Step). A detailed description of the estimation process, including the Hamilton filter and the Kim's smoothing algorithm may be found in Hamilton [1994].

The investigation of the zloty behaviour encompassed the identification of the long swings in the zloty, the verification of the uncovered interest parity hypothesis and the zloty bubble hypothesis. The analysis was based on the daily data of the period 04.03.1999. - 11.07.2001. The time series were taken from the National Bank of Poland. Estimation was conducted in GAUSS econometric package.

\section{Zloty appreciation and depreciation phases}

Zloty exchange rate movements were examined in terms of the zloty/dollar, the zloty/euro and the zloty/basket (50\%euro and $50 \%$ dollar) exchange rates (differences of natural logarithms of the raw data were taken). Following the Hamilton model assumptions, the time series of the underlying exchange rate was decomposed into appreciation and depreciation trends. Thus the model characteristics encompassed the means $\left(\mu_{1}\right.$ and $\left.\mu_{0}\right)$ and variances $\left(\sigma_{1}^{2}\right.$ and $\sigma_{0}^{2}$ ) of the exchange rate regimes (that is the appreciation and depreciation phases) as well as the transition probabilities between them ( $p$ and $q$ ). Results of the parameter estimates are presented in table 1.

Table 1. Appreciation and depreciation phases of the zloty/dollar, zloty/euro and zloty/basket exchange rates (standard errors in brackets).

\begin{tabular}{|l|l|l|l|}
\hline Parameter & USD & EUR & 50\%USD and 50\%EUR \\
\hline$\mu_{1}$ & $0.243(0.155)$ & $0.363(0.175)$ & $0.274(0.111)$ \\
\hline$\mu_{0}$ & $-0.033(0.028)$ & $-0.107(0.038)$ & $-0.075(0.022)$ \\
\hline$\sigma_{1}^{2}$ & $1.469(0.301)$ & $1.236(0.327)$ & $1.036(0.185)$ \\
\hline$\sigma_{0}^{2}$ & $0.268(0.03)$ & $0.288(0.049)$ & $0.166(0.019)$ \\
\hline$p$ & $0.852(0.059)$ & $0.777(0.103)$ & $0.826(0.067)$ \\
\hline$q$ & $0.964(0.014)$ & $0.947(0.031)$ & $0.953(0.02)$ \\
\hline
\end{tabular}

- appreciation (regime 0), +depreciation (regime 1) 
On the basis of the above results one concludes that means and variances differ within the distinguished states. Different parameter estimates of the zloty exchange rate vis-a-vis different basic currencies may result from their specific features - the market behaviour of the dollar exhibits different growth/fall patterns than those of the euro, explanation of which could be searched for in an analysis of the euro/dollar exchange rate. Figures in table 1 show that, without regard to the basic currency, probability of the zloty appreciation is higher than its depreciation probability. Probability of the zloty deprecation in the period $t$, provided the currency devalued in the period $t-1$, remains within the range 0.77 (PLN/EUR) and 0.85 (PLN/USD). The zloty appreciation in the period $t$, under the condition that the currency appreciated also in the previous period, fluctuates at around 0.95 in all cases.

The computed transition probabilities allow to derive the average length of the zloty appreciation and depreciation periods:

$$
\begin{aligned}
& a=\frac{1}{1-q}, \\
& d=\frac{1}{1-p},
\end{aligned}
$$

where:

$a$ - average appreciation period,

$d$ - average depreciation period.

Results can be seen in table 2 .

Table 2. Average length of the zloty appreciation and depreciation periods (in days).

\begin{tabular}{|c|c|c|c|}
\hline Phase & USD & EUR & 50\%USD and 50\%EUR \\
\hline Appreciation & 27.791 & 19.013 & 21.496 \\
\hline Depreciation & 6.746 & 4.419 & 5.742 \\
\hline
\end{tabular}

The zloty appreciation lasts about four times longer than the process of the currency weakening.

Figure 1 plots the behaviour of the Polish zloty against the background of its appreciation probabilities. 


\section{Uncovered interest parity}

The conducted analysis focused on the dynamics of nominal exchange rates and nominal interest rate spreads, which allowed for UIP hypothesis verification without making any assumptions on the price level. In the light of the EU enlargement and the processes of adjustment of the Polish financial markets to EU conditions, the core point of the study relates to the PLN/EUR exchange rate and return on 5 year Polish and EMU bonds.

According to the UIP hypothesis money kept in an account abroad (EMU countries) should, after the currencies exchange, yield the same rate of return as a deposit in the home country (Poland). A positive yield spread between Polish and EMU bonds should thus further the appreciation tendency of the zloty. This "classic" form of the UIP hypothesis was a starting point for the identification of periods, in which the exchange rate diverged from the equilibrium path described by the rates spread, denoting the possibility of bubble existence.

A GAUSS code of Hamilton was used in the estimation. The procedure enabled to make the distinction between the two regimes of a bivariate system, encompassing both the exchange rate and the rates spread. Estimation results are shown in table 3.

Table 3. Uncovered interest parity hypothesis (standard errors in brackets).

\begin{tabular}{|l|ll|ll|}
\hline & \multicolumn{3}{l|}{ Regime 1 } & \multicolumn{2}{l|}{ Regime 0 } \\
\hline Mean & & & \\
Exchange rate & $-0.049(0.033)$ & & $0.017(0.050)$ & \\
& $7.453(0.048)$ & & $9.2(0.060)$ & \\
\hline Variance-covariance matrix & 0.371 & 0.011 & 0.647 & 0.033 \\
& $(0.029)$ & $(0.021)$ & $(0.059)$ & $(0.034)$ \\
& & & & \\
& 0.011 & 0.373 & 0.033 & 0.455 \\
& $(0.021)$ & $(0.037)$ & $(0.034)$ & $(0.042)$ \\
\hline Probability $p$ (regime 1) and $q$ & $0.99(0.005)$ & & $0.987(0.007)$ & \\
(regime 0) & & & & \\
\hline
\end{tabular}

The obtained results do not confirm the UIP hypothesis (see table 3). Although appreciation and depreciation regimes were identified, the spreads, that correspond to them, do not correspond to the economic theory. Firstly, the yield spread is always positive, no matter what the current regime is. Secondly, even if one assumes that, without regard to exchange rate behaviour, a positive spread is characteristic for transition economies, then it should be expected, that the spread for appreciation periods should be bigger than for 
deprecation ones. However, it can be seen from table 3, that the average spreads are $7.45 \%$ and $9.2 \%$ for the appreciation and deprecation periods, respectively. Making the assumption, that exchange rate deviations from its equilibrium path are a result of speculation, one could conclude that speculators "play" at currency weakening. In the light of lack of consensus whether the uncovered interest parity hypothesis holds, and taking into account the macroeconomic situation, such an interpretation of the results should be treated with restraint.

Figure 2 pictures the exchange rate of the zloty vis-a-vis the euro, the PolishEuropean rates spread and the probability of Polish currency appreciation together with the corresponding spread.

\section{Zloty exchange rate bubbles}

The exchange rate bubble model consists of four regime-switching submodels, each of them corresponding to one variable. The variable set encompassed: the zloty/euro exchange rate, rates of return on $5 \mathrm{Y}$ Polish bonds, risk premium and the zloty/euro forward rate. The idea of the model was to identify periods, in which "joint" behaviour of all variables could provide evidence of a zloty bubble.

The detailed analysis of the zloty behaviour was outlined in section III. In the bubble model, it is assumed that the zloty might exhibit bubble properties in periods of prevailing appreciation or depreciation. The reason behind this was that the currency speculation is based on the technical analysis. Since there are no commonly accepted theoretical concepts explaining currency movements, especially in the short run, the majority of market participants employ technical analysis, copying current growth or decline trends, and thus contributing to bubble emergence.

The second submodel permitted an analysis of the rate of return on 5-year Polish bonds that could be regarded as a flexible proxy of rigid interest rates, fixed for a longer period. For the analysis differences of natural logarithms were taken.

The risk premium was computed as a spread between the rate of return on $5 Y$ Polish and Hungarian bonds. It was assumed that when investing capital, investors considered rates of return from safe securities in countries with similar macroeconomic situation.

The last submodel looked at a forward and spot exchange rate spread. The forward rate was calculated on the basis of daily quotas of WIBOR and EURIBOR rates. Since 
deviations of the spot rates from the forward rates are deterministic, and not stochastic (which implies that the currency markets are not effective (see Sławiński [1998])), first differences of natural logarithms were taken.

Parameter estimates are presented in table 4.

Table 4. Parameter estimates for the rate of return on $5 \mathrm{Y}$ bonds $(5 \mathrm{Y})$, the risk premium, the forward and spot rate spread $\left(r^{t}-r\right)$ (standard errors in brackets).

\begin{tabular}{|l|l|l|l|}
\hline Parameter & \multicolumn{1}{|c|}{$\mathbf{5 Y}^{*}$} & \multicolumn{1}{|c|}{ Risk premium } & \multicolumn{1}{c|}{$\boldsymbol{r}^{\boldsymbol{t}}-\boldsymbol{r}$} \\
\hline$\mu_{1}$ & 0.046 & $-1.268(0.037)$ & $0.564(0.433)$ \\
\hline$\mu_{0}$ & -0.001 & $4.13(0.073)$ & $-0.092(0.038)$ \\
\hline$\sigma_{1}^{2}$ & 0.633 & $0.210(0.02)$ & $16.648(3.006)$ \\
\hline$\sigma_{0}^{2}$ & 9.077 & $2.417(0.16)$ & $0.617(0.055)$ \\
\hline$p$ & 0.886 & $0.998(0.003)$ & $0.71(0.084)$ \\
\hline$q$ & 0.566 & $0.999(0.002)$ & $0.948(0.015)$ \\
\hline
\end{tabular}

* it was impossible to compute standard errors, since the Hesjan was not positively defined

The regime 1 denotes phases of the growing rate of return on bonds and the regime 0 - the falling ones. The rate of return on bonds grows on average by $0.05 \%$ a day. It falls by $0.001 \%$ in period $t$, provided, it was also falling in period $t-1$. The probability of its growth is higher than its decline probability.

When analysing the risk premium, two periods were identified. Until October 1999 it was more favourable to invest in Hungary than in Poland, since the interest rate spread was negative and accounted for $1.27 \%$ on average. After October 1999 the rate of return on Polish bonds was higher than the rate of return on their Hungarian counterparts - the spread reached the level of $4.16 \%$ on average.

The difference between the forward and the spot exchange rate fell and grew by $0.09 \%$ and $0.56 \%$ on average, respectively. The probability of the declining trend was higher than the probability of the growing one -0.95 and 0.71 , respectively.

Figure 3 illustrates the realisations of the variables together with the probabilities of the regime, in which a speculative bubble could emerge. The starting point for the analysis is the zloty appreciation probability, in regard to which other variables' movements are examined. It is assumed that the zloty is "contaminated" by a speculative bubble in period t, if its appreciation probability is high (close to 1) and if at the same time, the probabilities of 
the movement of other variables, corresponding (on the basis of the economic theory) to the zloty weakening are also high (that is probability of the falling returns on bonds, probability of the negative spread between the rates of return on Polish and Hungarian bonds, and probability of the declining difference between the forward and the spot rates).

The model identifies periods of peculiar behaviour of the zloty in February, October and November 2000. The high probability of the zloty appreciation (see figure 3) was not confirmed by such a high probability of the growing returns on Polish bonds. The risk premium analysis shows that investors should have tended to invest in Poland since October 1999. According to the made assumption, the positive spread between the returns on Polish and Hungarian bonds, could justify the zloty appreciation in the periods, in which purported bubbles could appear. However, taking into consideration movements of other variables, condition on the risk premium should not be regarded as a decisive one. The analysis of the spread between the forward and the spot exchange rates provides positive evidence for a possible speculative bubble of the zloty, since the probability of the lasting falling trend of the examined spread was relatively high.

To verify the bubble hypothesis, there were also factors surveyed that did not enter the model explicite, but behaviour of which could explain the zloty movements in the periods, when the currency seemed to be over- or undervalued.

Polish currency strengthening at the beginning of the year 2000 occurred despite unfavourable data on the current account deficit in January. Macroeconomic indicators were ambiguous, which had a destabilising impact on the market and could contribute to the intensification of speculation.

The zloty appreciation in the period 13-16 October 2000 is difficult to explain with the general economic and political conditions. The situation on the international financial market worsened, which resulted from oil price increases and decreases of stock exchange indices and led to the outflow of capital from Poland. In conjunction with the postponement of the budgetary debate at the Polish Parliament, the zloty appreciation in October 2000 may be regarded as unfounded.

The appreciation in the period 2-6 November could have been a result of the release of favourable data on the Polish balance of payments. However, the information on the deficit did not have the same impact on the zloty/dolar exchange rate, which could confirm the hypothesis that the zloty/euro behaviour had different background. 
The unfounded depreciation phases of the zloty/euro exchange rate were identified in an analogous manner. The probability of the exchange rate depreciation was compared with the probability of the growth of the return on bonds, the probability of a positive spread between returns on Polish and Hungarian bonds, and the probability of growth of the spread between the forward and the spot exchange rate. The periods of the purported bubble existence were 31 March-5 April 2000, 19-23 April 2001 and 6-11 July 2001.

The analysis of factors, exogenous to the model, shows that the depreciation in the period 31 March-5 April could have resulted from the release of worse, than expected, data on the current account, as well as opinions on the exchange rate expressed by members of the economic and political circles in Poland.

Determinants of the zloty depreciation in April 2001 are difficult to identify. The currency weakening could have been caused by the euro/dollar movements. However, although interest rates in the United States were diminished, the European currency depreciated.

The model does not allow to determine factors behind the zloty depreciation in the period 6-11 July 2001. Taking into account the general macroeconomic situation, one could assume that the weakening of the zloty resulted from speculative operations.

The presented model of speculative bubbles could be a starting point for an analysis of the zloty movements in regard to speculators' behaviour. The stochastic linkages between the variables (in form of the transition probabilities) allow for the enrichment of the study of deterministic relations, enabling better understanding of the zloty changes.

\section{Conclusion}

This paper provides an empirical framework for a short-run analysis of the zloty behaviour and speculative phenomena in Poland. Defining a set of exchange rate bubble determinants and constructing an econometric model of regime switching type enabled empirical verification of speculative operations on the Polish currency market.

Daily movements of the zloty were investigated in terms of the long swings, that is the time series of the zloty was decomposed into appreciation and depreciation phases. The results suggest that the zloty exchange rate is characterised by interweaving periods of appreciation and depreciation. The appreciation phase lasts around 20 days and is a gradual process. The depreciation phases are shorter and more rapid. 
To analyse speculative fluctuations of the Polish currency the uncovered interest parity was verified and a model of a possible zloty bubble was developed.

The analysis does not provide empirical evidence that the uncovered interest parity hypothesis holds. Taking into account the current economic situation, the divergence of the exchange rate from its equilibrium value cannot, however, be interpreted as an evidence for speculative bubbles of the Polish zloty.

On the basis of the results obtained from the constructed bubble model, one could identify periods, in which the zloty exhibited "bubble properties": 3-7 February, 13-17 October and 2-6 November 2001 (appreciation periods), and 31 March-5 April 2000, 19-23 April 2001 and 6-11 July 2001 (depreciation periods). Thus, speculative operations may have been conducted at that time, which, in conjunction with the shallow market of the Polish zloty seems to be highly probable.

\section{Literature Cited}

Engel C.M., Hamilton J.D. [1989], Long swings in the dollar: are they in the data and do markets know it?, The American Economic Review, vol.80, p.689-713

Funke M., Hall S. Sola M. [1994], Rational Bubbles during Poland,s Hyperinflation. Implications end Empirical Evidence, The European Economic Review, vol. 38, p.12571276

Hall S., Psaradakis Z., Sola M. [1999], Detecting periodically collapsing bubbles: a Markovswitching unit root test, Journal of Applied Econometrics, vo.14, p.143-154.

Hamilton J.D. [1994], Time Series Analysis, Princeton University Press, Princeton

Schaller H., van Norden S. [1997], Fads or Bubbles?, Working Paper 97-2, Bank of Canada

Sławiński A. [1998], Globalizacja rynków finansowych a polityka pieniężna, Bank i Kredyt, p. 61.

Van Norden S. [1996], Regime Switching as a Test for Exchange Rate Bubbles, Journal of Applied Econometrics, vol. 11, p.219-251.

Welfe A., Narel S. [1994], The statistical properties of free market zloty/dollar exchange rate: the Polish experience, Przeglad Statystyczny, vol. 41, nr 4, p.401-412. 
Figure 1. Zloty exchange rate and its appreciation probability.
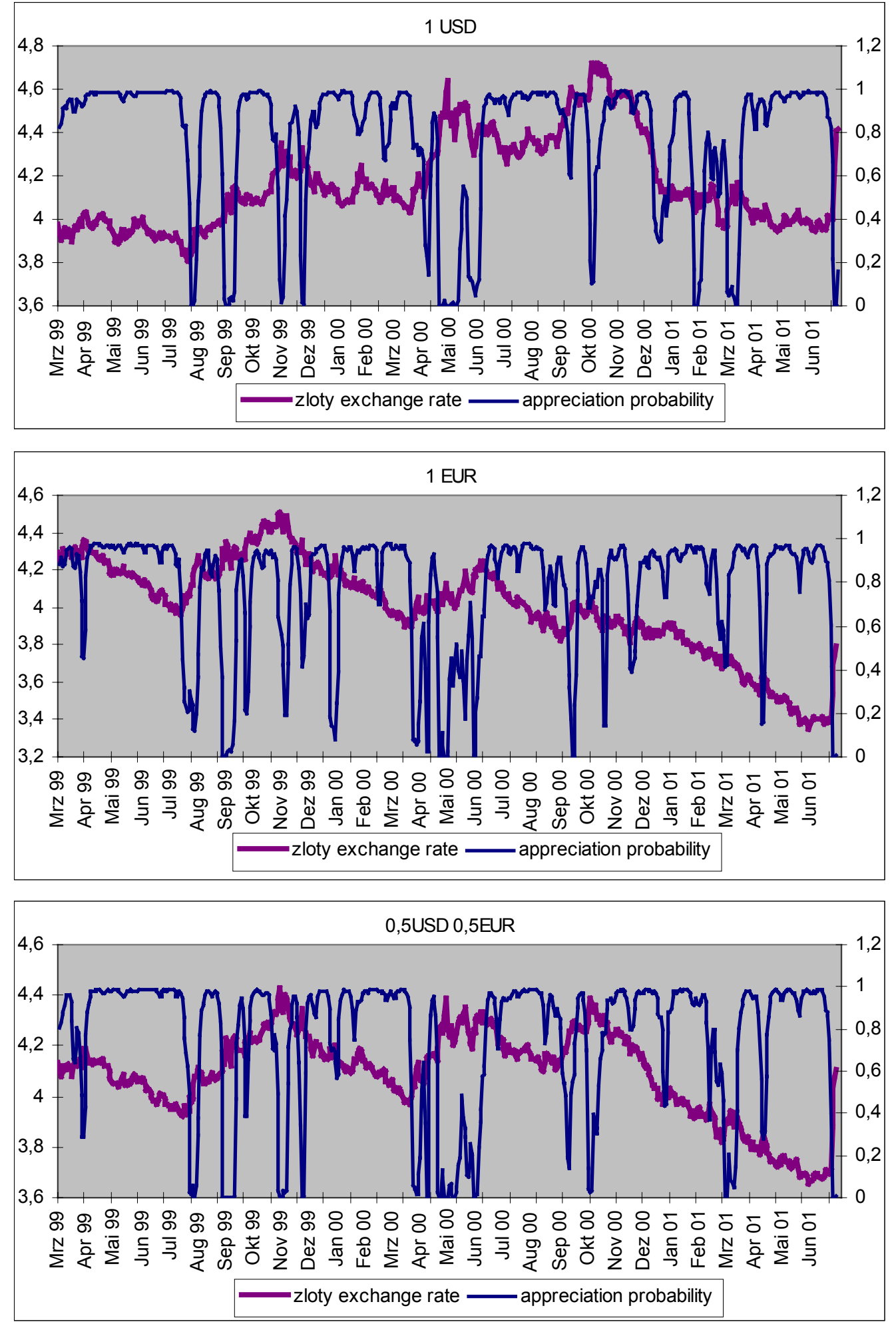
Figure 2. Uncovered interest parity hypothesis.
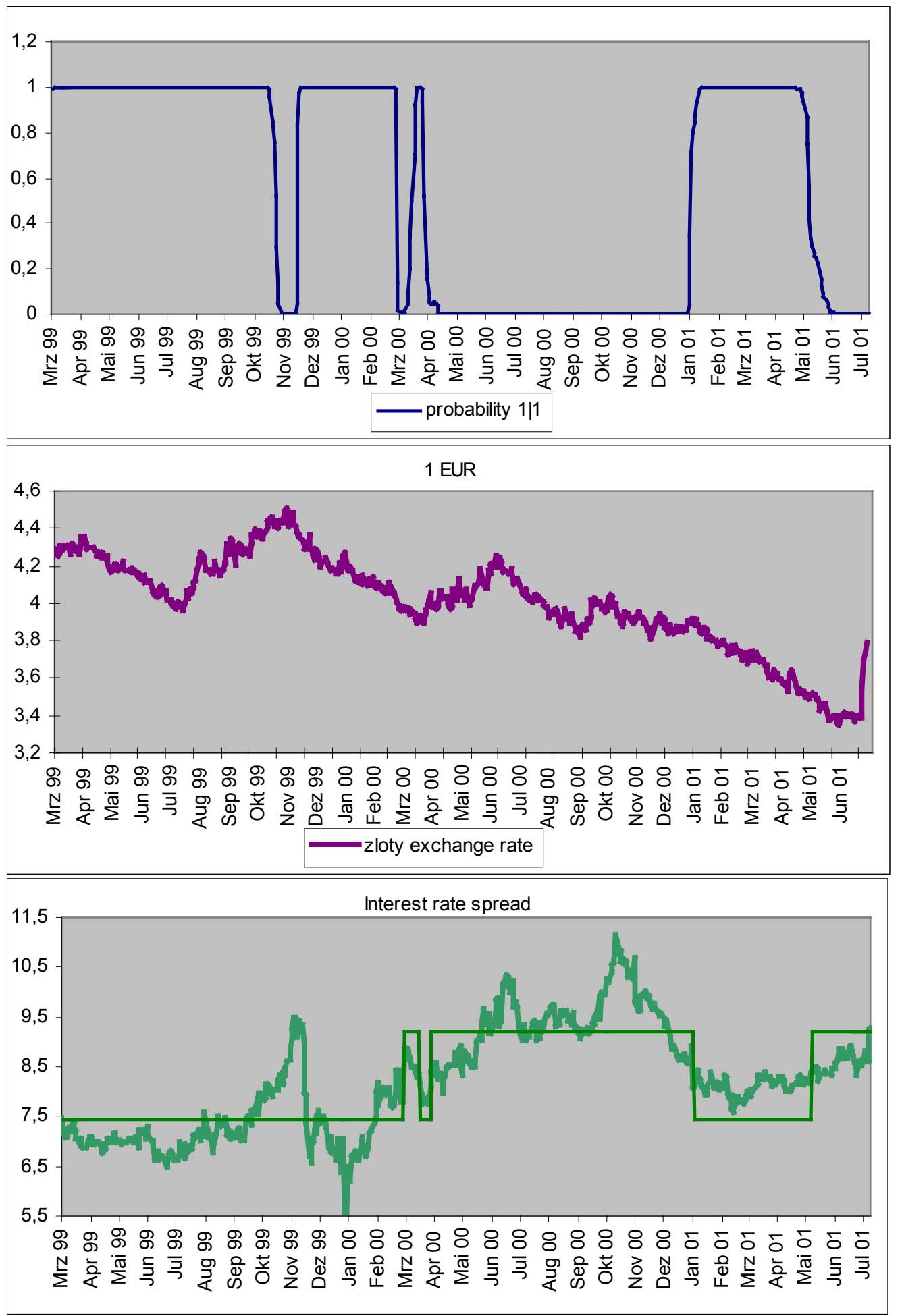
Figure 3. Zloty bubble hypothesis.

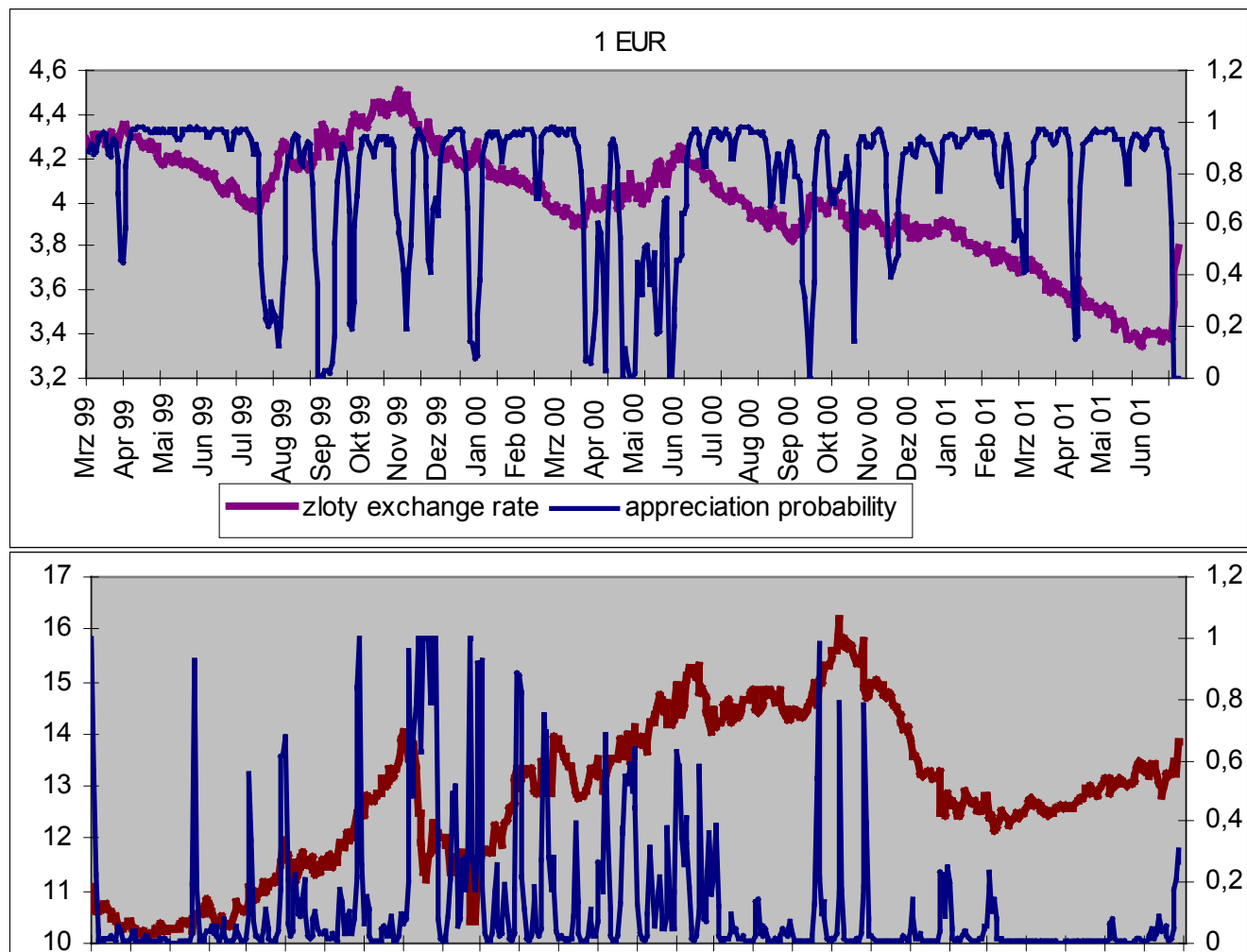

৪ ৪ ৪ে ৪ে ৪ে ৪ ৪ ৪৪ ৪ ৪ ৪ ৪ ৪ ৪ ৪ চ

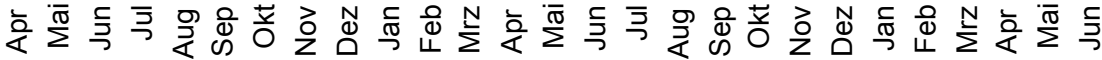

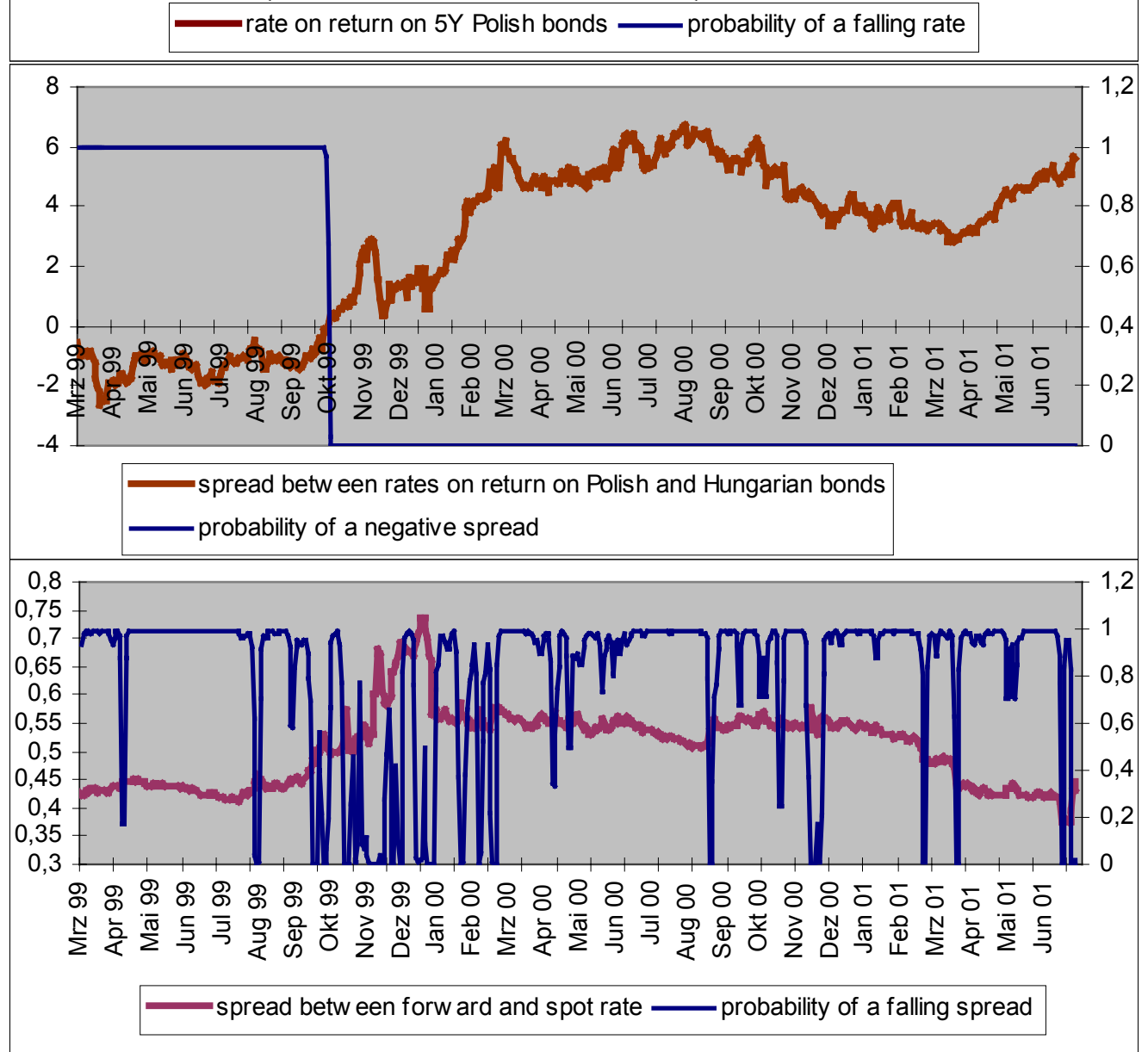

